\title{
CpG site DNA methylation patterns reveal a novel regulatory element in the mouse prion protein gene
}

\author{
Wuyun DALAI ${ }^{1)}$, Eiko MATSUO ${ }^{1)}$, Natsumi TAKEYAMA ${ }^{2)}$, Junichi KAWANO ${ }^{1)}$ and \\ Keiichi SAEKI ${ }^{1) *}$ \\ 1)Laboratory of Microbiology and Immunology, Graduate School of Agricultural Science, Kobe University, 1-1 \\ Rokkodai-cho, Nada-ku, Kobe, Hyogo 657-8501, Japan \\ 2) Research Department, Nippon Institute for Biological Science, 9-2221-1 Shinmachi, Ome, Tokyo 198-0024, \\ Japan
}

J. Vet. Med. Sci.

79(1): 100-107, 2017

doi: $10.1292 / j v m s .16-0390$

Received: 26 July 2016

Accepted: 15 September 2016

Published online in J-STAGE:

26 September 2016
ABSTRACT. The cellular isoform of the prion protein $\left(\operatorname{PrP}^{\mathrm{C}}\right)$ plays critical roles in the development of prion disorders. Although PrP mRNA is ubiquitously present in a tissue-specific manner, the DNA methylation of $\operatorname{PrP}$ gene (Prnp) is still unknown. In this study, we demonstrated that the $\mathrm{CpG}$ island (CGl, positioned at -218 to +152 bp from the transcriptional start site) including the Prnp core promoter region was completely unmethylated in all tested tissues. On the other hand, CpG methylation in the CGI shore region (positioned at -599 to -238 bp) occurred in various tissue- and site-specific proportions. Interestingly, the correlation analysis between CpG methylation status and PrP mRNA levels showed that one CpG site methylation at -576 was negatively correlated with the PrP mRNA level (Pearson's $r=-0.374, P=0.035$ ). Taken together, our results suggest that Prnp is a typical housekeeping gene and various methylation frequencies of the CGI shore region are likely to affect Prnp expression in a tissue-specific manner.

KEY WORDS: epigenetics, DNA methylation, prion, prion protein gene

The cellular prion protein $\left(\mathrm{PrP}^{\mathrm{C}}\right)$ is a ubiquitous glycosylphosphatidylinositol (GPI)-anchored cell surface N-linked glycoprotein [27]. The physiological roles of $\operatorname{PrP}^{\mathrm{C}}$ remain elusive, but several reports have proposed some functions including anti-apoptosis [20], reduction of oxidative stress [19], cell adhesion [12] and copper cooperative neuroprotection [9]. Although the prion protein gene (Prnp) is predominately expressed in the central nervous system (CNS) by all known mammals, the pattern of gene activation is still poorly understood. The distribution of Prnp expression in various tissues has been analyzed in many mammals, including hamsters, sheep, mice and cattle [3, 7, 14, 29]. Prnp expression in the mouse brain is increased 4-fold in the period from birth to 3 weeks of age, and this higher level is maintained throughout adulthood [21, 22]. The mouse Prnp localized on chromosome 2 consists of three exons, with the third exon encoding the entire open reading frame [30]. In addition, the chromosome 2 including Prnp is closely linked to the incubation period of prion disease in mice [5, 6]. In mouse and rat Prnp, the region upstream of the first exon consists of high GC content including CCAAT box and three SP1 binding sites that have been shown to regulate the core promoter activity $[2,23]$. However, there has been no epigenetic study including an investigation of DNA methylation on Prnp.

DNA methylation on the cytosine of $\mathrm{CpG}$ dinucleotides is an epigenetic modification that plays an important role in embryonic development, tumorigenesis, aging and other neurodegenerative disorders [1, 11, 13, 24]. A large number of vertebrate genes have been analyzed with respect to $\mathrm{CpG}$ frequency, the length of $\mathrm{CpG}$ islands (CGIs) and the presence of DNA methylation on housekeeping genes and tissue-specific genes [17]. In addition, $\mathrm{CpG}$ methylation is an epigenetic mark generally considered to induced transcriptional gene silence by inhibiting the association of DNA binding factors [4]. In order to address the effect of CpG methylation on Prnp expression, we investigated the correlation between the CpG methylation status and Prnp expression level in mouse tissues.

\section{MATERIALS AND METHODS}

Mice

C57BL/6CrSlc and BALB/cCrSlc mice were purchased from Japan SLC. (Hamamatsu, Japan). Five male and five female

*Correspondence to: Saeki, K., Laboratory of Microbiology and Immunology, Graduate School of Agriculture, Kobe University, 1-1 Rokkodai-cho, Nada-ku, Kobe, Hyogo 657-8501, Japan. e-mail: Saeki@pegasus.kobe-u.ac.jp

(c2017 The Japanese Society of Veterinary Science

This is an open-access article distributed under the terms of the Creative Commons Attribution Non-Commercial No Derivatives (by-ncnd) License <http://creativecommons.org/licenses/by-nc-nd/4.0/>. 
mice aged 8 weeks were used in all experiments. The mouse studies were approved by the Ethical Committee for the Use of Experimental Animals of Kobe University (authorization number, 23-06-03). All efforts were made to minimize animal suffering and to reduce the number of animals. Each tissue was stored at $-80^{\circ} \mathrm{C}$ until used.

\section{DNA extraction and bisulfite sequencing PCR}

Genomic DNA samples were extracted from each mouse tissue using a PureLink Genomic DNA Kit (Thermo Fisher Scientific, Yokohama, Japan) according to the manufacturer's instructions. Genomic DNA samples were quantified and stored at $-20^{\circ} \mathrm{C}$ until used. DNA samples (3 $\mu \mathrm{g}$ ) were then treated with bisulfite using a MethylEasy Xceed Rapid DNA Bisulfite Modification Kit (Takara, Otsu, Japan), and the bisulfite-treated DNA was used as a template for PCR. The PCR experiment was performed in a $50 \mu l$ reaction mixture containing 1.25 units of EpiTaq HS polymerase (Takara), $5 \mu l$ of $10 \times$ EpiTaq PCR Buffer, $2.5 \mathrm{mM} \mathrm{MgCl}$, $1.2 \mathrm{mM}$ dNTP, $0.4 \mu \mathrm{M}$ of each primer and $50 \mathrm{ng}$ of template DNA. The PCR primers for amplifying the bisulfite-converted mouse Prnp region were MePrP-1F ( -682 to -661 ) (5'-GTGGGAGTTGTTAAATGTAGTG-3'), MePrP-1R ( -154 to -175 ) (5'-CCCCAATATCAACACTCCCTAA-3'), MePrP-2F (-236 to -215) (5'-GGAGTATTGGGTATTGGATTAG-3') and MePrP-2R $(+347$ to +325$)\left(5^{\prime}\right.$-CCAAAAACAATCAAAAAATACCA-3') (Fig. 1A). PCR reactions were performed using the primer pair of MePrP-1F and MePrP-1R or MePrP-2F and MePrP-2R, followed by 40 cycles of $98^{\circ} \mathrm{C}$ for $10 \mathrm{sec}, 60^{\circ} \mathrm{C}$ for $30 \mathrm{sec}$ and $72^{\circ} \mathrm{C}$ for $30 \mathrm{sec}$. The PCR product was purified from 1.8\% agarose gels using a Wizard ${ }^{\circledR}$ SV Gel and PCR Clean-Up System Kit (Promega, Tokyo, Japan) and then subjected to direct sequencing.

The sequencing reaction $(20 \mu l)$ was carried out using $40 n$ g of template DNA, $4.5 \mu l$ of BigDye Terminator v.3.1 Cycle Sequencing Kit (Thermo Fisher Scientific), $0.16 \mu \mathrm{M}$ primer (MePrP-1F, MePrP-1R, MePrP-2F or MePrP-2R) and the following protocol: $96^{\circ} \mathrm{C}$ for $1 \mathrm{~min}$, followed by 25 cycles of $96^{\circ} \mathrm{C}$ for $10 \mathrm{sec}, 50^{\circ} \mathrm{C}$ for $5 \mathrm{sec}$ and $60^{\circ} \mathrm{C}$ for $4 \mathrm{~min}$. The sequencing product was then run on an ABI prism 3130 Genetic Analyzer (Thermo Fisher Scientific). The percentage of methylation at each CpG site was calculated as the peak height of $C$ divided the sum of the peak heights of $C$ and $T, 100 \times C /(C+T)$, as shown in the computergenerated raw sequencing chromatogram [16]. DNA methylation standards were prepared from cloned plasmid to mimic different methylation levels of CpG sites. To obtain the plasmid DNA standards, bisulfite-treated DNAs prepared from RAW264.7 cells were amplified by PCR using the primer pair of MePrP-1F and MePrP-1R, and cloned into the pMD20 plasmid. After sequencing analysis, two of these clones were derived from completely methylated and unmethylated for the CpG sites. Two plasmids were mixed and sequenced to mimic different DNA methylation percentages: $0,10,20,30,40,50,60,70,80,90$ and $100 \%$.

\section{$R N A$ extraction and real-time quantitative RT-PCR}

Total RNA was isolated from each type of tissue using an RNeasy Plus Mini Kit (Qiagen, Tokyo, Japan) and was stored at $-80^{\circ} \mathrm{C}$ until used.

Real-time quantitative RT-PCR (qRT-PCR) was performed with a Thermal Cycler Dice Real Time System TP800

(Takara) using One Step SYBR ${ }^{\circledR}$ PrimeScrip PLUS RT-PCR kit (Takara). The primer pairs for qRT-PCR were 5'-TCCAATTTAGGAGAGCCAAGC-3' and 5'-GCCGACATCAGTCCACATAG-3' for mouse Prnp mRNA and 5'-AGCCAAGCACATACACCAAA-3' and 5'-GGGTTTAGACCGTCGTGAGA-3' for 28S rRNA, respectively. The PCR amplification was carried out in a $25 \mu \mathrm{l}$ reaction mixture containing $5 \mathrm{ng}$ (for 28S rRNA) or $50 \mathrm{ng}$ (for Prnp) of total RNA, 0.4 $\mu \mathrm{M}$ of each primer, $12.5 \mu l$ of $2 \times$ One Step RT-PCR Buffer 4, $1.5 \mu l$ of TaKaRa Ex Taq HS Mix and $0.5 \mu l$ of PrimeScript PLUS RTase Mix. The PCR conditions consisted of an initial reverse transcription step for 5 min at $42^{\circ} \mathrm{C}$ and a polymerase activation step for $10 \mathrm{sec}$ at $95^{\circ} \mathrm{C}$, followed by 45 cycles of $95^{\circ} \mathrm{C}$ for $5 \mathrm{sec}$ and $65^{\circ} \mathrm{C}$ for $30 \mathrm{sec}$. Both dissociation curve analysis and agarose gel electrophoresis were used to check the specificity of the qRT-PCR.

\section{Statistical analysis}

Statistical analysis was performed using Student's $t$-test. Significance was defined as $P<0.01$. Pearson's correlation analysis was performed to investigate the relationship between DNA methylation levels of CpG sites and mRNA expression of Prnp. A $P$-value $<0.05$ was considered statistically significant.

\section{RESULTS}

\section{Cp G site methylation status of the Prnp promoter region in mouse tissues}

To investigate sense-strand CpG site methylation in Prnp, we performed bisulfite sequencing PCR amplification of regions ( -682 to -154 and -236 to +347 ) using two pairs of primers (Fig. 1A). This region contained a total of forty-six CpG dinucleotides numbered from $\mathrm{CpG} 1$ to $\mathrm{CpG} 46$. The sequence search revealed that the CGI spanned between nucleotides -218 and $+152(370$ bp), a region containing thirty-two CpG sites (CpGs 9 to 40 and -180 to +142$)$ and the entire length of the first exon ( +1 to +67$)$. No other CGIs were present in $\sim 5 \mathrm{~kb}$ of either the upstream or downstream regions around the first exon.

To verify and calibrate the status of every $\mathrm{CpG}$, we prepared and sequenced two reference plasmids containing the complete methylated or non-methylated gene at CpGs 1 to 4 (positions $-599,-576,-336$ and -326) (Fig. 1B). The percentage of observed methylation at every $\mathrm{CpG}$ site was calibrated to the expected methylation rate by the equations described in Fig. $1 \mathrm{~B}$. The methylation analysis of the forty-six CpG sites $(-599$ to +286$)$ in thirty-four C57BL/6 mouse tissues showed that CpGs 8 to 46 $(-238$ to +286$)$ containing the CGI (CpGs 9 to 40) were completely unmethylated in all tissue samples, whereas CpGs 1 to 7 exhibited various methylation statuses in a tissue-specific manner (Fig. 2A and 2B). The complete absence of CGI methylation in 
A

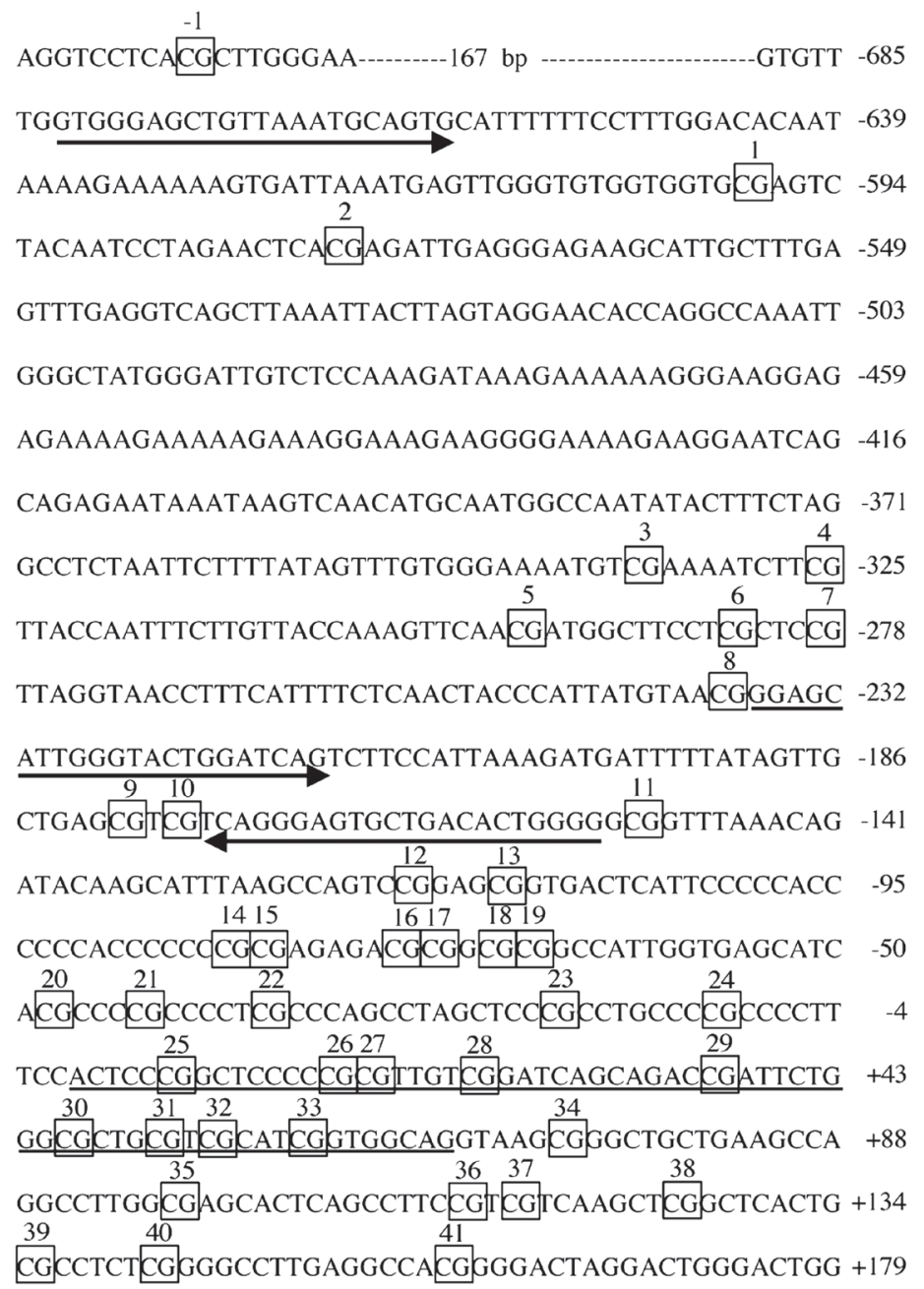

GACTGGGGCTGAGTCTGGCTGGGAGGTGACTGTACACCCCCTGCTG +225 4243 CGCGACTCCTGGAGGAACCGAATCCCAGGGCAGCCAGGCCGGGAG +270 CCAGCCTTTCCTTCCEGAGCCAGATTCACAGCTCAGCATCGCTGGG +316 GATGGGGGTGGCATCTTTTGACTGTCCTTGGCTGTTTTCTTCTCTC +362

B

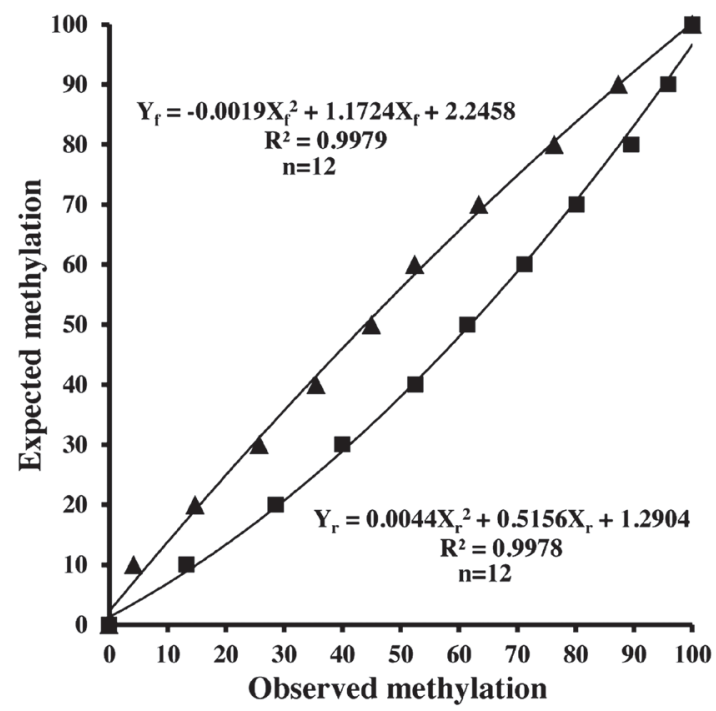

Fig. 1. CpG dinucleotide positions on the mouse Prnp target gene and curve relationship between observed and expected methylation. (A) Positions of the $\mathrm{CpG}$ motif are indicated as open boxes and numbered from -1 to 46 . Underlining and arrows denote the first exon and bisulfite PCR primer regions, respectively. Numbers on the right indicate nucleotide positions relative to the transcription initiation site of the Prnp gene. (B) Two approximate curves represent the relationships between observed and expected methylation status based on the results of resulting of multiple mixing experiments. Solid squares and triangles are plotted against the expected value using the forward and reverse sequencing primers, respectively. Each plot is shown as the average of twelve independent experiments. 
A

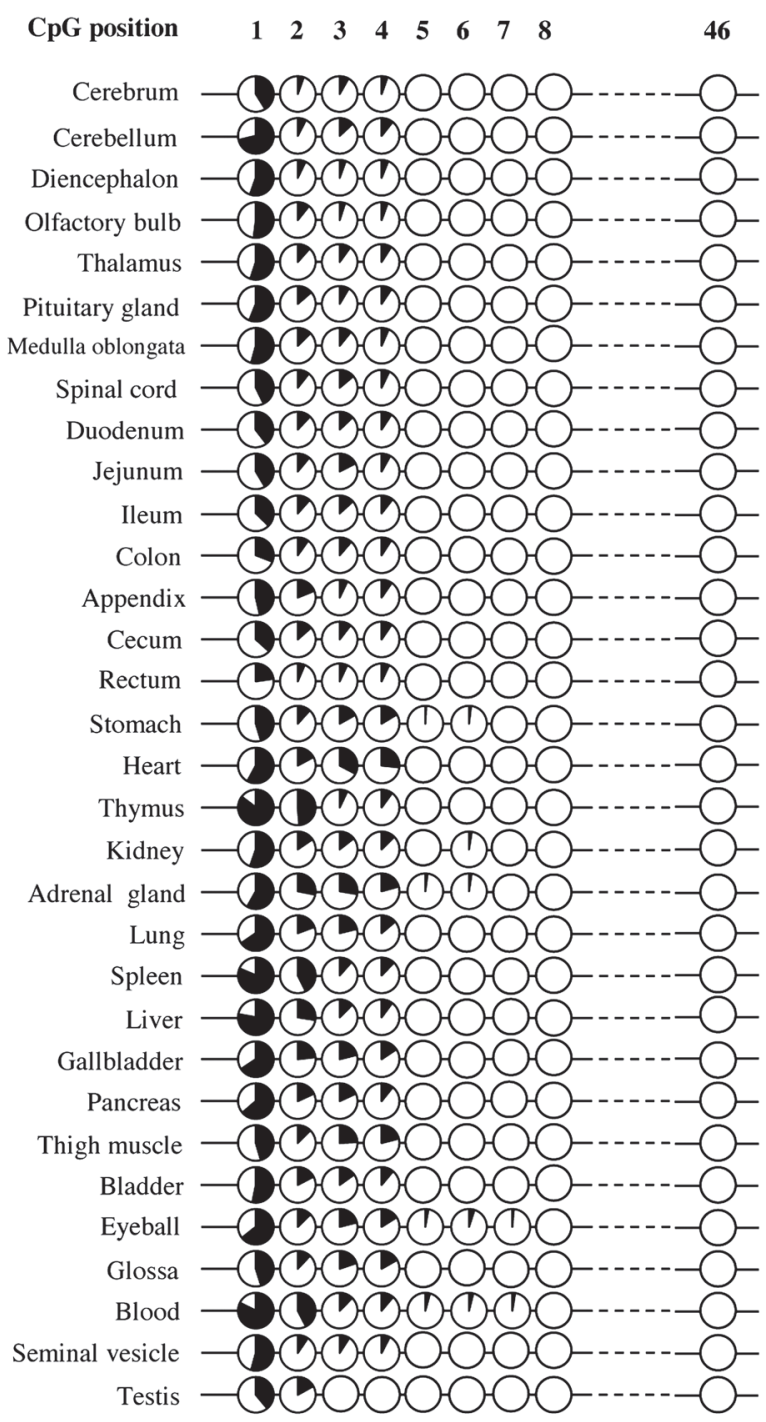

B

Female

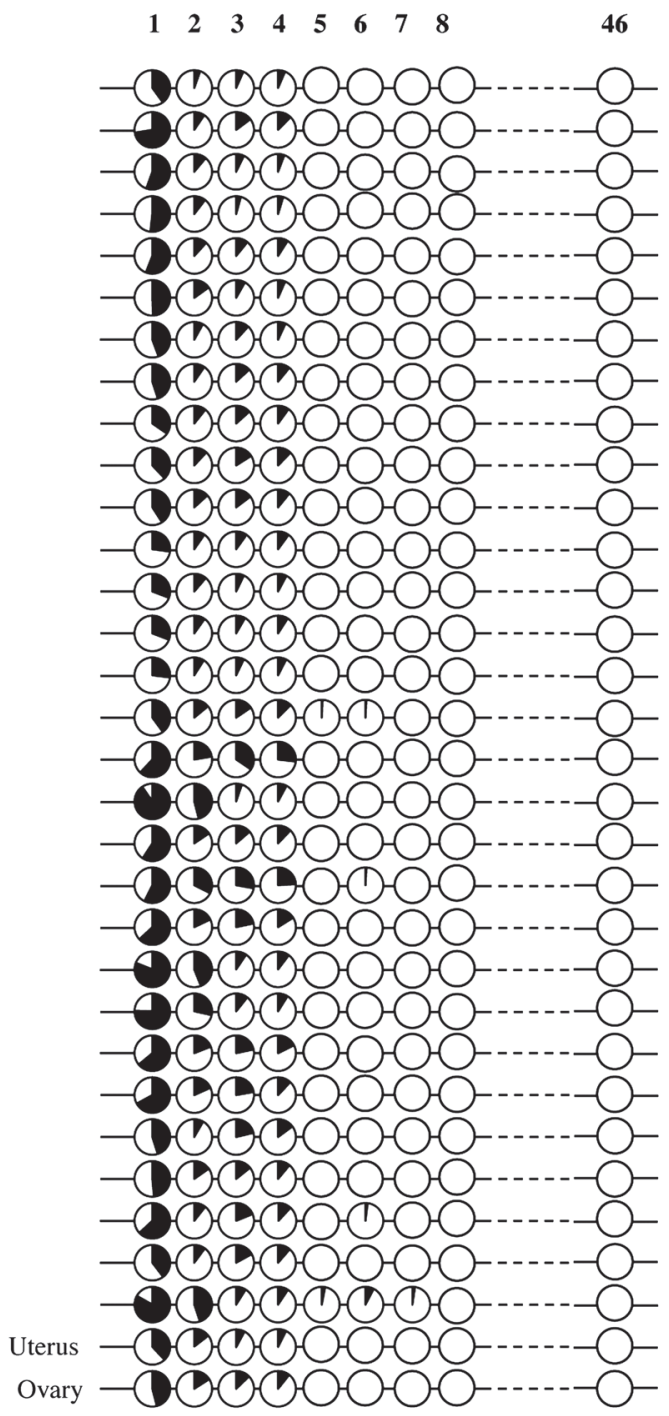

Fig. 2. CpG site- and tissue-specific methylation status in mice. Pie charts representing the percentage methylation at each CpG position are shown. The methylation ratio is shown as a black region representing the average of six analyzed values from each of two males (A) and females (B). Pie charts of $\mathrm{CpG}$ sites 9 to 45 are not included, because these sites were unmethylated.

all tissues indicated that Prnp was a typical house-keeping gene. In addition, the methylation statuses of the respective forty-six CpGs were shown to be not significantly different between male and female mouse tissues $(P>0.01)$. The partial methylation of CpGs 1 to 4 among mouse tissues ranged from $\sim 23 \%$ to $89 \%$ (average 53\%), $\sim 5 \%$ to $47 \%$ (average 17\%), $0 \%$ to $34 \%$ (average $14 \%$ ) and $0 \%$ to $27 \%$ (average 11\%), respectively. Only in testis, CpGs 3 and 4 were completely unmethylated. At CpGs 5 to 7 , very low levels of methylation were found in the stomach, kidney, adrenal gland, eyeball and blood. In the cerebrum and liver only, we also investigated the $\mathrm{CpG}$ methylation of an additional upstream region $(-1,379$ to -758$)$ in Prnp. This fragment contained six CpG sites $(-1,275,-1,273,-1,271,-1,182$ and -864$)$ that showed $100 \%$ methylations.

\section{Correlation between the CpG site methylation and Prnp expression}

To evaluate the degree of correlation between the $\mathrm{CpG}$ site methylation and Prnp transcripts, we also performed quantitative real-time RT-PCR (qRT-PCR) analysis of Prnp in thirty-four individual tissue samples from C57BL/6 mice (Fig. 3A). To assess the expression levels of Prnp, the 28S rRNA mRNA was chosen as the reference transcript, because it is conveniently assayed. To avoid spurious PCR amplification from mouse genomic DNA, we designed the PCR forward and reverse primers located in the first exon and second exon for Prnp, and fifth exon and sixth exon for $28 \mathrm{~S}$ rRNA, respectively. Prnp transcripts were readily detected in all samples and varied considerably among the different tissues. The highest amount of Prnp mRNA was found in the cerebrum (100), followed by the cerebellum (79.5 \pm 17.7$)$, diencephalon (68.3 \pm 19.4$)$, olfactory bulb (50.4 \pm 19.8$)$, medulla oblongata (49.0 \pm 9.8$)$, thalamus $(35.8 \pm 8.3)$, spinal cord (29.6 \pm 9.8$)$ and pituitary gland $(22.7 \pm 5.2)$. The lowest level of Prnp 
A

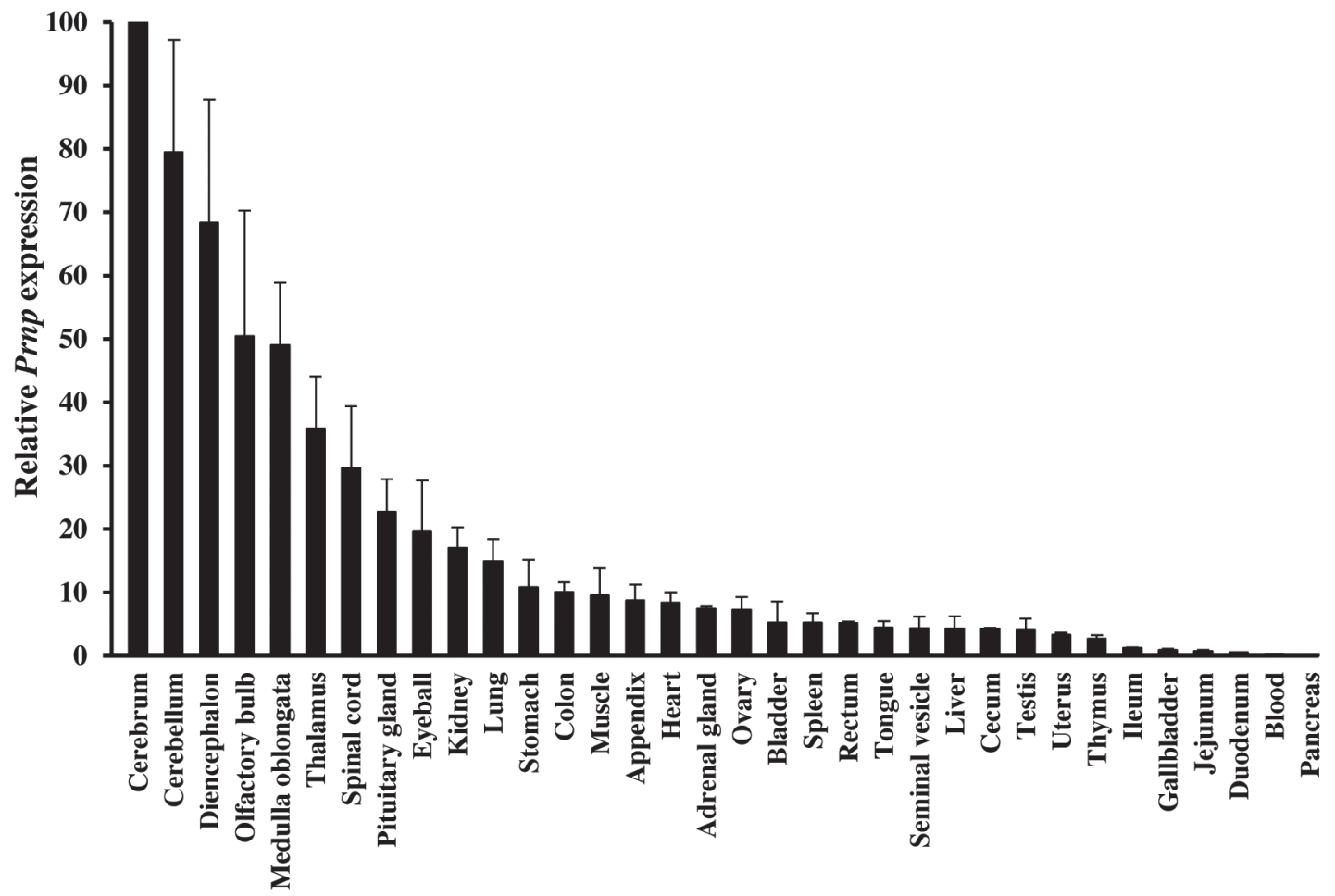

B

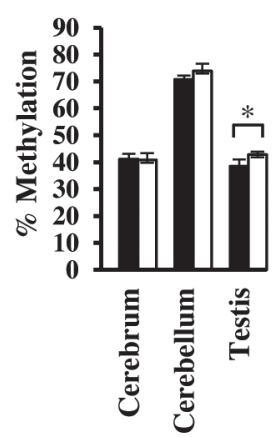

C

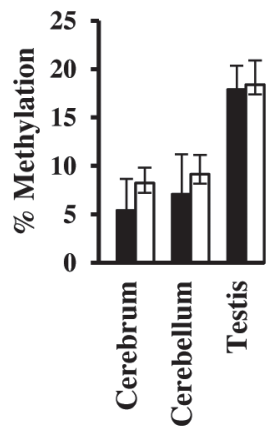

D

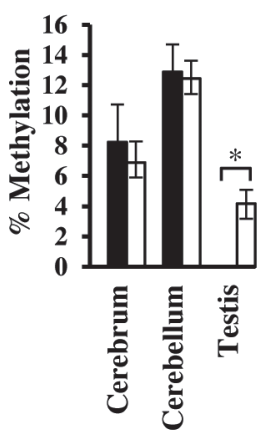

E

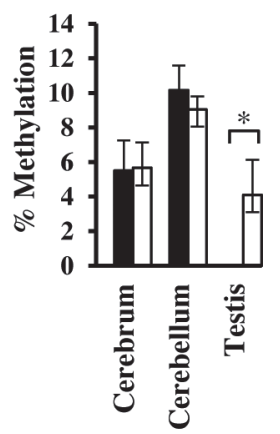

F

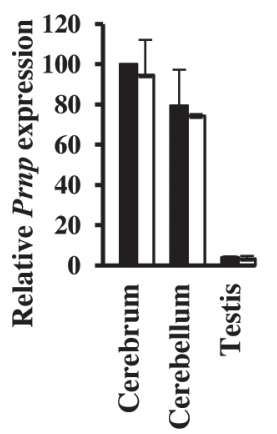

Fig. 3. Mouse Prnp gene expression in each type of mouse tissue and comparison of DNA methylation between C57BL/6 and BALB/c mice. (A) The Prnp mRNA level in the cerebrum is presented as 100. Data are presented as the means \pm SD and obtained from three independent experiments from male mice, except for the ovary and uterus. Comparison of the methylation levels at CpG positions 1 (B), 2 (C), 3 (D) and 4 (E) in C57BL/6 (solid bars) and BALB/c (open bars) mice. ${ }^{*} P<0.01$, Student's $t$-test. (F) Comparison of Prnp gene expression in C57BL/6 (solid bars) and $\mathrm{BALB} / \mathrm{c}$ (open bars) mice. All data are presented as the means $\pm \mathrm{SD}$.

transcripts was detected in the pancreas $(0.10 \pm 0.003)$, followed by the blood $(0.14 \pm 0.04)$, duodenum $(0.5 \pm 0.1)$, jejunum $(0.7 \pm$ $0.2)$ and gallbladder $(0.9 \pm 0.2)$. In other tissues, Prnp expression levels ranged from $1.3 \%$ to $19.6 \%$ that in the cerebrum.

Based on the qRT-PCR results and the calculated methylation percentages for individual $\mathrm{CpG}$ sites, we performed a correlation analysis (Table 1). The results revealed a significant negative correlation between $\mathrm{CpG}$ site methylation at position $2(-576)$ and Prnp mRNA expression (Pearson's $r=-0.374, P=0.035$ ), but no significant correlations were observed between methylation and Prnp mRNA level at CpG 1 or CpGs 3-7 ( $P>0.05)$. The location of CpG 2 was composed of the sequence CACGAG termed the N-box which bound predictively with the basic helix-loop-helix (bHLH) family of transcription factors [15]. No other CpG positions ( $\mathrm{CpG} 1$ and $\mathrm{CpGs} 3-46)$ were present in the N-box regulatory elements (Fig. 1A). In addition, the sequences CACGAG did not exist within $5 \mathrm{~kb}$ of the first exon of Prnp in either direction. Moreover, the sequence GAGGG (position between -569 and $-565)$ with an oppositely oriented CCCTC motif was located in close proximity to CpG 2 ( -576 ), which was predicted to bind with the CCCTC-binding factor (CTCF) involved in insulator activity [8]. The CTCF binding motif was also found at the Prnp 
Table 1. Correlation analysis between methylation and expression of Prnp

\begin{tabular}{llrrrrrr}
\hline & CpG 1 & $\boldsymbol{C p} \boldsymbol{G ~ 2}$ & \multicolumn{1}{c}{ CpG 3 } & CpG 4 & \multicolumn{1}{c}{ CpG 5 } & CpG 6 & CpG 7 \\
\hline Pearson's $(r$-values $)$ & 0.064 & $-\mathbf{0 . 3 7 4}$ & -0.264 & -0.285 & -0.142 & -0.142 & -0.114 \\
$P$-value & 0.730 & $\mathbf{0 . 0 3 5}$ & 0.145 & 0.115 & 0.437 & 0.437 & 0.535 \\
\hline
\end{tabular}

Pearson's $r$-values $\geq \pm 0.3$ and $P$-values $\leq 0.05$ are considered to indicate significant correlations. CpG 2 , where methylation is negatively correlated with Prnp expression, is shown in bold and italic.

core promoter region (position between -40 and -36 ).

\section{Differential Prnp methylation in the testis between C57BL/6 and BALB/C}

To further characterize Prnp CpG methylation and expression in the testis, we also performed bisulfite sequencing PCR and qRT-PCR in several BALB/c mouse tissues. Methylation analysis of a total of forty-six CpG sites in the BALB/c cerebrum, cerebellum and testis revealed that CpGs 5 to 46 were also completely unmethylated like those of C57BL/6 mice. Statistical analysis showed that the methylation statuses of CpGs 1 to 4 in both the cerebrum and cerebellum were not significantly different between C57BL/6 and BALB/c mice (Fig. 3B-3E). On the other hand, the methylation ratios of Prnp in the BALB/c testis were calculated as $42.8 \pm 1.1 \%$ for $\mathrm{CpG} 1,18.4 \pm 2.5 \%$ for $\mathrm{CpG} 2,4.2 \pm 0.9 \%$ for $\mathrm{CpG} 3$ and $4.1 \pm 2.0 \%$ for CpG 4 . We found that DNA in the BALB/c mouse testis was significantly more methylated in CpGs $1(P=0.0008), 3\left(P=5.0 \times 10^{-7}\right)$ and $4(P=0.0005)$ than that in the $\mathrm{C} 57 \mathrm{BL} / 6$ mouse testis, whereas the $\mathrm{CpG} 2$ site showed similar methylation percentages between the two mouse lines $(P=0.727)$. In the cerebrum, cerebellum and testis, qRT-PCR analysis of Prnp mRNA levels showed no significant differences between $\mathrm{C} 57 \mathrm{BL} / 6$ and BALB/c mice (Fig. 3F). These results suggested that the differential methylation statuses of CpGs 1,3 and 4 had no discernible impact on Prnp expression in the testis between C57BL/6 and BALB/c. These investigations together with the correlation results suggested that no significant difference of methylation at $\mathrm{CpG} 2$ site between the two mouse lines might lead to the same extent of Prnp expression in testes.

\section{DISCUSSION}

This study is the first report to describe an association between the DNA methylation on CpGs and Prnp gene expression. The CGIs located at the gene promoter region in housekeeping genes are constitutively unmethylated, whereas the tissue-specific genes are methylated in most cells [17]. In the present study, Prnp was confirmed to be a typical housekeeping gene by demonstrating the absence of $\mathrm{CpG}$ methylation in the entire CGI (CpGs 9 to 40), including the core promoter region (CpGs 20 to 24) (Fig. 2).

In general, enhancer regions tend to have mostly $\mathrm{CpG}$-poor and variable methylation conditions termed low-methylated regions (LMRs) [26]. Our results suggested that one of the Prnp enhancer regions was localized at -599 to -279 (CpGs 1 to 7) with varying methylation status among tissues. In fact, CpG $2(-576)$ was located in a CpG-poor region in a differentially methylated region, and its methylation status was negatively correlated with Prnp expression (Table 1). Interestingly, only the CpG 2 site between CpG 1 and $\mathrm{CpG} 46$ was located above the sequence CACGAG, which is termed the N-box and binds to members of the bHLH family of transcription repressors, such as HES-1 (mouse homologue of Drosophila hairy and Enhancer of split 1 protein) [15]. While the negative correlation between CpG 2 methylation at a repressor element and Prnp expression is difficult to explain, it may suggest that Prnp transcriptional regulation is associated in some way with HES-1. HES-1 influences the maintenance of neural stem and progenitor cells and thereby plays a major role in CNS development [18]. The Hes ImRNA is present at a high level in the mouse embryonal neuroepithelium proliferating neural precursor cells, whereas its expression is very low in the adult CNS [25].

On the one hand, Prnp mRNA in mouse embryos is detected in the CNS and peripheral nervous system where is localized with differentiated neuronal cells. In addition, Prnp expression is dramatically increased after birth until 3 weeks of age and then maintained at a consistent level throughout adulthood [21,22]. As seen above, the regulation of Prnp expression follows quite a different pattern than that of Hes 1 expression during the fetal and adult stages in the nervous system. Our finding that CpG 2 methylation is negatively correlated with Prnp expression, suggests that an unknown enhancer factor might bind to the N-box and shelter it from the effects of transcriptional repressors, such as HES proteins, in order to promote high level Prnp expression in the CNS.

In N2a mouse neuroblastoma cells, artificially overproduced HES-1 has been shown to dramatically reduce the expression of Prnp [31]. Our sequence data for N2a cells showed that Prnp was identical to that of Fig. 1. Moreover, the promoter analysis for I/LnJ mouse Prnp showed that the deletion from -663 to -537 resulted in about 1.5 -fold increase in activity [2]. However, the Prnp fragment derived from I/LnJ mouse has a base substitution from "CG" to "GG" at CpG 2 (-576) position, resulting in the destruction of N-box consensus sequence [15]. Further researches are needed to be confirmed whether this single-nucleotide polymorphism affects Prnp expression at various steps in mouse. Interestingly, a recent report suggests that HES-1 is switched from a transcriptional repressor to a transcriptional activator to induce the expression of cartilage catabolic factor genes including Adamts 5, Mmp13, Il6 and Il1rl1 [28]. Our observations imply that an expected protein binding to the Prnp N-box might act as a transcriptional enhancer but not a repressor in the adult mouse stage.

We also found that a motif (position -569 to -565 ) for the CTCF termed the insulator element was situated close to the CpG 2 site (position -576). The CCCTC insulator has been well-described as an element that interferes with the interaction between 
an enhancer (or a repressor) and a promoter [10]. CTCF also participates in chromatin organization and remodeling, contributing to the repression or activation of gene transcription [8]. Although it is necessary to determine what kind of transcriptional factors would bind to the sequence CACGAGATTGAGGG and its reverse complement CCCTCAATCTCGTG, the CpG 2 site methylation might play an important role in the regulation of Prnp gene expression.

In conclusion, we have demonstrated that the CGI of Prnp is completely unmethylated and that CpG methylation at nucleotide position -576 ( $\mathrm{CpG} 2$ ) appears to act as an important regulator of Prnp expression. Although comparable phenomena have remained unclear in the human and bovine PrP gene $(P R N P)$, the C57BL/6 strain is of particular importance as a prion infection model in addition to a source of transgenic and knockout mice. Therefore, our findings provide novel information on the epigenetics of the Prnp gene and could ultimately contribute to elucidation of the molecular pathogenesis of prion diseases and the development of effective treatments.

ACKNOWLEDGMENT. This work was supported by Japan Society for the Promotion of Science KAKENHI Grant Number JP24580445.

\section{REFERENCES}

1. Ammal Kaidery, N., Tarannum, S. and Thomas, B. 2013. Epigenetic landscape of Parkinson's disease: emerging role in disease mechanisms and therapeutic modalities. Neurotherapeutics 10: 698-708. [Medline] [CrossRef]

2. Baybutt, H. and Manson, J. 1997. Characterisation of two promoters for prion protein (PrP) gene expression in neuronal cells. Gene 184: 125-131. [Medline] [CrossRef]

3. Bendheim, P. E., Brown, H. R., Rudelli, R. D., Scala, L. J., Goller, N. L., Wen, G. Y., Kascsak, R. J., Cashman, N. R. and Bolton, D. C. 1992. Nearly ubiquitous tissue distribution of the scrapie agent precursor protein. Neurology 42: 149-156. [Medline] [CrossRef]

4. Bird, A. 2007. Perceptions of epigenetics. Nature 447: 396-398. [Medline] [CrossRef]

5. Büeler, H., Aguzzi, A., Sailer, A., Greiner, R. A., Autenried, P., Aguet, M. and Weissmann, C. 1993. Mice devoid of PrP are resistant to scrapie. Cell 73: 1339-1347. [Medline] [CrossRef]

6. Carlson, G. A., Ebeling, C., Torchia, M., Westaway, D. and Prusiner, S. B. 1993. Delimiting the location of the scrapie prion incubation time gene on chromosome 2 of the mouse. Genetics 133: 979-988. [Medline]

7. Ford, M. J., Burton, L. J., Morris, R. J. and Hall, S. M. 2002. Selective expression of prion protein in peripheral tissues of the adult mouse. Neuroscience 113: 177-192. [Medline] [CrossRef]

8. Franco, M. M., Prickett, A. R. and Oakey, R. J. 2014. The role of CCCTC-binding factor (CTCF) in genomic imprinting, development, and reproduction. Biol. Reprod. 91: 125. [Medline] [CrossRef]

9. Gasperini, L., Meneghetti, E., Pastore, B., Benetti, F. and Legname, G. 2015. Prion protein and copper cooperatively protect neurons by modulating NMDA receptor through S-nitrosylation. Antioxid. Redox Signal. 22: 772-784. [Medline] [CrossRef]

10. Gaszner, M. and Felsenfeld, G. 2006. Insulators: exploiting transcriptional and epigenetic mechanisms. Nat. Rev. Genet. 7: 703-713. [Medline] [CrossRef]

11. Gopalakrishnan, S., Van Emburgh, B. O. and Robertson, K. D. 2008. DNA methylation in development and human disease. Mutat. Res. 647: 30-38. [Medline] [CrossRef]

12. Graner, E., Mercadante, A. F., Zanata, S. M., Forlenza, O. V., Cabral, A. L., Veiga, S. S., Juliano, M. A., Roesler, R., Walz, R., Minetti, A., Izquierdo, I., Martins, V. R. and Brentani, R. R. 2000. Cellular prion protein binds laminin and mediates neuritogenesis. Brain Res. Mol. Brain Res. 76: 85-92. [Medline] [CrossRef]

13. Hannum, G., Guinney, J., Zhao, L., Zhang, L., Hughes, G., Sadda, S., Klotzle, B., Bibikova, M., Fan, J. B., Gao, Y., Deconde, R., Chen, M., Rajapakse, I., Friend, S., Ideker, T. and Zhang, K. 2013. Genome-wide methylation profiles reveal quantitative views of human aging rates. Mol. Cell 49: 359-367. [Medline] [CrossRef]

14. Horiuchi, M., Yamazaki, N., Ikeda, T., Ishiguro, N. and Shinagawa, M. 1995. A cellular form of prion protein $\left(\operatorname{PrP}^{\mathrm{C}}\right)$ exists in many non-neuronal tissues of sheep. J. Gen. Virol. 76: 2583-2587. [Medline] [CrossRef]

15. Iso, T., Kedes, L. and Hamamori, Y. 2003. HES and HERP families: multiple effectors of the Notch signaling pathway. J. Cell. Physiol. 194: 237-255. [Medline] [CrossRef]

16. Jiang, M., Zhang, Y., Fei, J., Chang, X., Fan, W., Qian, X., Zhang, T. and Lu, D. 2010. Rapid quantification of DNA methylation by measuring relative peak heights in direct bisulfite-PCR sequencing traces. Lab. Invest. 90: 282-290. [Medline] [CrossRef]

17. Jones, P. A. 2012. Functions of DNA methylation: islands, start sites, gene bodies and beyond. Nat. Rev. Genet. 13: 484-492. [Medline] [CrossRef]

18. Kageyama, R., Ohtsuka, T. and Kobayashi, T. 2008. Roles of Hes genes in neural development. Dev. Growth Differ. 50 Suppl 1: S97-S103. [Medline] [CrossRef]

19. Klamt, F., Dal-Pizzol, F., Conte da Frota, M. L. Jr., Walz, R., Andrades, M. E., da Silva, E. G., Brentani, R. R., Izquierdo, I. and Fonseca Moreira, J. C. 2001. Imbalance of antioxidant defense in mice lacking cellular prion protein. Free Radic. Biol. Med. 30: 1137-1144. [Medline] [CrossRef]

20. Kuwahara, C., Takeuchi, A. M., Nishimura, T., Haraguchi, K., Kubosaki, A., Matsumoto, Y., Saeki, K., Matsumoto, Y., Yokoyama, T., Itohara, S. and Onodera, T. 1999. Prions prevent neuronal cell-line death. Nature 400: 225-226. [Medline] [CrossRef]

21. Lazarini, F., Deslys, J. P. and Dormont, D. 1991. Regulation of the glial fibrillary acidic protein, beta actin and prion protein mRNAs during brain development in mouse. Brain Res. Mol. Brain Res. 10: 343-346. [Medline] [CrossRef]

22. Manson, J., West, J. D., Thomson, V., McBride, P., Kaufman, M. H. and Hope, J. 1992. The prion protein gene: a role in mouse embryogenesis? Development 115: 117-122. [Medline]

23. Saeki, K., Matsumoto, Y., Matsumoto, Y. and Onodera, T. 1996. Identification of a promoter region in the rat prion protein gene. Biochem. Biophys. Res. Commun. 219: 47-52. [Medline] [CrossRef]

24. Sanchez-Mut, J. V. and Gräff, J. 2015. Epigenetic Alterations in Alzheimer's Disease. Front. Behav. Neurosci. 9: 347. [Medline] [CrossRef]

25. Sasai, Y., Kageyama, R., Tagawa, Y., Shigemoto, R. and Nakanishi, S. 1992. Two mammalian helix-loop-helix factors structurally related to Drosophila hairy and Enhancer of split. Genes Dev. 6 12B: 2620-2634. [Medline] [CrossRef]

26. Stadler, M. B., Murr, R., Burger, L., Ivanek, R., Lienert, F., Schöler, A., van Nimwegen, E., Wirbelauer, C., Oakeley, E. J., Gaidatzis, D., Tiwari, V. 
K. and Schübeler, D. 2011. DNA-binding factors shape the mouse methylome at distal regulatory regions. Nature 480: 490-495. [Medline]

27. Stahl, N., Borchelt, D. R., Hsiao, K. and Prusiner, S. B. 1987. Scrapie prion protein contains a phosphatidylinositol glycolipid. Cell 51: 229-240. [Medline] [CrossRef]

28. Sugita, S., Hosaka, Y., Okada, K., Mori, D., Yano, F., Kobayashi, H., Taniguchi, Y., Mori, Y., Okuma, T., Chang, S. H., Kawata, M., Taketomi, S., Chikuda, H., Akiyama, H., Kageyama, R., Chung, U. I., Tanaka, S., Kawaguchi, H., Ohba, S. and Saito, T. 2015. Transcription factor Hes1 modulates osteoarthritis development in cooperation with calcium/calmodulin-dependent protein kinase 2. Proc. Natl. Acad. Sci. U.S.A. 112: 3080-3085. [Medline] [CrossRef]

29. Tichopad, A., Pfaffl, M. W. and Didier, A. 2003. Tissue-specific expression pattern of bovine prion gene: quantification using real-time RT-PCR. Mol. Cell. Probes 17: 5-10. [Medline] [CrossRef]

30. Westaway, D., Cooper, C., Turner, S., Da Costa, M., Carlson, G. A. and Prusiner, S. B. 1994. Structure and polymorphism of the mouse prion protein gene. Proc. Natl. Acad. Sci. U.S.A. 91: 6418-6422. [Medline] [CrossRef]

31. Wright, J. A., McHugh, P. C., Stockbridge, M., Lane, S., Kralovicova, S. and Brown, D. R. 2009. Activation and repression of prion protein expression by key regions of intron 1. Cell. Mol. Life Sci. 66: 3809-3820. [Medline] [CrossRef] 